\title{
Length of stay and readmission in older adults hospitalized for heart failure
}

\author{
Cherinne Arundel $1^{1,2,3}$, Phillip H. Lam ${ }^{1,3,4}$, Charles Faselis ${ }^{1,2}$, Helen M. Sheriff ${ }^{1,2}$, Daniel. J. Dooley ${ }^{3,4}$, \\ Charity Morgan ${ }^{1,5}$, Gregg C. Fonarow ${ }^{6}$, Wilbert S. Aronow ${ }^{7,8}$, Richard M. Allman ${ }^{2,5}$, Ali Ahmed ${ }^{1,2,3}$
}

\author{
${ }^{1}$ Veterans Affairs Medical Center, Washington, DC, USA \\ ${ }^{2}$ George Washington University, Washington, DC, USA \\ ${ }^{3}$ Georgetown University, Washington, DC, USA \\ ${ }^{4}$ MedStar Washington Hospital Center, Washington, DC, USA \\ ${ }^{5}$ University of Alabama at Birmingham, Birmingham, AL, USA \\ ${ }^{6}$ University of California, Los Angeles, CA, USA \\ ${ }^{7}$ Weschester Medical Center, Valhalla, NY, USA \\ ${ }^{8}$ New York Medical College, Valhalla, NY, USA
}

Submitted: 20 February 2019; Accepted: 5 June 2019

Online publication: 8 January 2020

Arch Med Sci 2021; 17 (4): 891-899

DOI: https://doi.org/10.5114/aoms.2019.89702

Copyright $\odot 2019$ Termedia \& Banach

\section{Abstract}

Introduction: Hospital length of stay (LOS) and hospital readmissions are metrics of healthcare performance. We examined the association between these two metrics in older patients hospitalized with decompensated heart failure (HF).

Material and methods: Eight thousand and forty-nine patients hospitalized for HF in 106 U.S. hospitals had a median LoS of 5 days; among them, 3777 had a LoS $>5$ days. Using propensity scores for LoS $>5$ days, we assembled 2723 pairs of patients with LoS $1-5$ vs. $>5$ days. The matched cohort of 5446 patients was balanced on 40 baseline characteristics. We repeated the above process in 7045 patients after excluding those with LoS > 10 days, thus assembling a second matched cohort of 2399 pairs of patients with LoS $1-5$ vs. $6-10$ days. Hazard ratios (HR) and $95 \%$ confidence intervals $(\mathrm{CI})$ for outcomes associated with longer LoS were estimated in matched cohorts.

Results: In the primary matched cohort $(n=5446)$, LoS $>5$ days was associated with a higher risk of all-cause readmission at 30 days $(H R=1.16$; $95 \% \mathrm{Cl}: 1.04-1.31 ; p=0.010$ ), but not during longer follow-up. A longer LoS was also associated with a higher risk of mortality during 8.8 years of follow-up $(\mathrm{HR}=1.13 ; 95 \% \mathrm{Cl}: 1.06-1.21 ; p<0.001)$. LoS had no association with $\mathrm{HF}$ readmission. Similar associations were observed among the matched sensitivity cohort $(n=4798)$ that excluded patients with LoS $>10$ days.

Conclusions: In propensity score-matched balanced cohorts of patients with $\mathrm{HF}$, a longer LoS was independently associated with poor outcomes, which persisted when LoS > 10 days were excluded.

Key words: length of stay, 30-day all-cause readmission, heart failure, allcause mortality.

\section{Introduction}

Heart failure (HF) is the leading cause for 30-day all-cause readmission among older patients in the United States [1], the reduction of which is a focus of the Affordable Care Act, the 2010 comprehensive health care reform law [2]. Hospitals, on the other hand, are also encouraged by the

\author{
Corresponding author: \\ Cherinne Arundel MD \\ Washington DC VA \\ Medical Center \\ 50 Irving St \\ NW, Washington \\ DC 20422, USA \\ Phone: 1-202-745-8386 \\ E-mail: Cherinne.Arundel@ \\ va.gov
}


Medicare Inpatient Prospective Payment System to have a shorter length of stay (LOS) [3, 4], which has been shown to be variously associated with outcomes [5-7]. In the current study, we examined the association between LoS and hospital readmission, two metrics of healthcare performance, in a propensity score-matched cohort of hospitalized patients with HF.

\section{Material and methods}

\section{Data source and study population}

Data for the study were collected from the Alabama Heart Failure Project, a registry of Medicare beneficiaries hospitalized for $\mathrm{HF}$ in the state of Alabama, the details of which have been previously published [8-10]. Briefly, extensive baseline data were collected on 8555 discharged patients from 106 Alabama hospitals during 1998-2001 with a principal discharge diagnosis of HF [11-13]. Medicare beneficiaries are the recipients of the United States government program called Medicare that provides health care coverage to American citizens 65 years or older, and to certain younger people with disability or permanent kidney failure requiring dialysis or a transplant [14].

\section{Study variables}

Data on baseline characteristics including comorbidities, medications, laboratory, and in-hospital events were collected by chart abstraction. Our exposure variable was LoS, which was calcu- lated by subtracting the date of admission from the date of discharge. Of the 8049 patients discharged alive, 3777 had longer than median LoS of 5 days (25-75 percentile, 4-8 days; 5-95 percentile, 2-15 days; 1-99 percentile, 2-25 days; Figure 1). Our outcome variables included all-cause readmission, HF readmission, all-cause mortality, and the combined endpoint of all-cause readmission or mortality. All outcomes were examined at 30 days, 12 months, and during the overall 8.8 (median $=2.5$ ) years of follow-up. Information on outcome events and times to those events were obtained from the Medicare data files [8].

\section{Assembly of a balanced study cohort}

We assembled a primary propensity scorematched cohort in which patients with a longer and a shorter LoS would be balanced on key measured baseline characteristics [15-17]. We estimated propensity scores for LoS > 5 days for each of the 8049 patients using a logistic regression model based on 40 baseline characteristics displayed in Figure 2 $[17,18]$. We then used a greedy matching protocol to match 2723 patients with LoS $>5$ days with another 2723 patients who had LoS of $1-5$ days and similar propensity scores, thus assembling a matched cohort of 5446 patients (Figure 1) [19, 20].

\section{Assembly of a balanced sensitivity cohort}

To determine whether the results of the study could be replicated after excluding a potentially sicker cohort of patients with long LoS, we repeat-

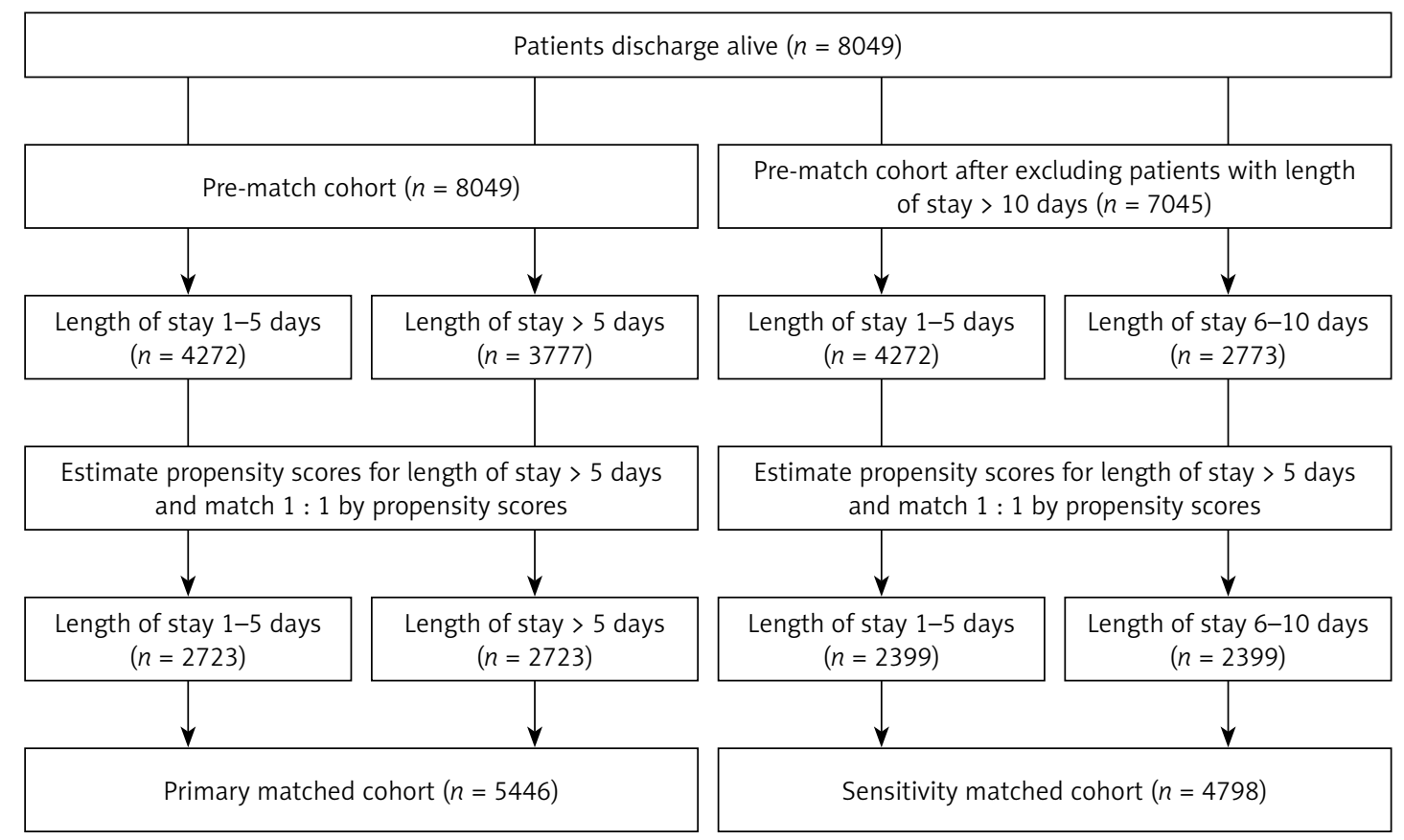

Figure 1. Flow chart displaying assembly of primary matched cohort of patients with heart failure by hospital length of stay $1-5$ versus $>5$ days and sensitivity matched cohort of patients with heart failure by hospital length of stay $1-5$ versus $6-10$ days 
ed the above process in 7045 patients after excluding those with LoS > 10 days. Of these, 2773 had LoS 6-10 days (Figure 1). The assembled second sensitivity matched cohort of 2399 pairs of patients with LoS $1-5$ vs. $6-10$ days was also balanced on 40 baseline characteristics.

\section{Statistical analyses}

Pearson $\chi^{2}$ and Wilcoxon rank-sum tests were used for descriptive analyses to compare between-group differences in baseline characteristics as appropriate. Kaplan-Meier survival plots for all-cause mortality by the two LoS categories during the overall follow-up of 8.8 (median $=2.5$ ) years were generated using the primary matched data. Cox regression models were used to estimate hazard ratios (HR) and 95\% confidence intervals $(\mathrm{Cl})$ for outcomes associated with longer LoS in both matched cohorts. We also examined the association of LoS with the primary outcome among the 8049 pre-match patients using Cox regression models, separately adjusting for propensity scores and the 40 variables used to estimate propensity scores. We then fitted restricted cubic spline models with 4 knots at 3, 5 (reference), 7 and 10 days to assess nonlinearity of the relationship of LoS with mortality during 8.8 (median $=2.5$ ) years of follow-up.

To examine whether significant associations observed in our matched data could be explained away by an unmeasured baseline characteristic, we conducted formal sensitivity analyses using Rosenbaum's approach [21]. From the 2723 pairs of matched patients, we identified pairs in which we could directly compare survival times within the pair to determine whether one member of the pair clearly had a longer survival or event-free survival than the other member. We then used the sign-score test to calculate "sensitivity bounds" for a hypothetical unmeasured confounder to determine how much it would need to increase the odds of having a longer LoS to explain away any significant association between LOS and outcomes. A significant sign-score test provides strong evidence of a relationship between longer LoS and time to death. Our sensitivity analysis assumes that the potential unmeasured confounder is a binary baseline characteristic that is a near perfect predictor of the outcomes and also not strongly correlated with any of the 40 baseline characteristics used in our propensity score model. However, sensitivity analysis cannot determine whether such an unmeasured confounder exists. All statistical tests were two-tailed with a $p$-value $<0.05$ considered significant. IBM SPSS Statistics for Windows, Version 25 (IBM Corp. Armonk, NY) and SAS version 9.4 (SAS Institute Inc., Cary, NC) were used for data analyses.

\section{Results}

\section{Baseline characteristics}

Patients in our propensity score-matched cohort $(n=5446)$ had a mean age of $75.8 \pm 10.8$ years, $58 \%$ were female, and $25 \%$ were African American. Prior to matching, HF patients with LoS $>5$ days were older and had a higher prevalence of comorbidities and in-hospital events (Table I). Post-match absolute standardized differences were $<10 \%$ for all 40 measured baseline characteristics, suggesting no residual consequential imbalance between the two LoS groups (Figure 2). After matching, patients in the sensitivity cohort were also balanced on all 40 measured baseline characteristics.

\section{Length of stay and readmission in the matched primary cohort}

30 -day all-cause readmission occurred in $20 \%$ and $23 \%$ of matched patients with LoS 1-5 and $>5$ days, respectively (hazard ratio $(H R)=1.16$; 95\% confidence interval $(\mathrm{Cl}): 1.04-1.31 ; p=0.010$; Table II). Findings from our sensitivity analyses demonstrate that the significant associations of LoS > 5 days and 30-day all-cause readmission were insensitive to unmeasured confounders. Of the 2723 matched pairs, in 965 pairs we were able to determine which patient within a matched pair had a shorter 30-day total readmission-free survival, and in 55\% (528/965) of those pairs, they belonged to the longer LoS group (sign-score test $p=0.003$ ). A hidden baseline characteristic would need to increase the odds of having a longer LoS by $6 \%$. HR $(95 \% \mathrm{Cl})$ for 30 -day all-cause readmission associated with LOS as a continuous variable in the matched data was 1.02 (1.01-1.04; $p<0.001)$.

In the pre-match cohort, multivariable-adjusted and propensity score-adjusted HRs (95\% Cls) for 30-day all-cause readmission associated with LoS $>5$ days were both $1.19(1.07-1.32 ; p=0.001)$. LoS had no association with 30-day HF readmission. Associations of a longer LoS and all-cause readmission at 12 months and during 8.8 (median $=2.5$ ) years of follow-up are displayed in Table II.

30-day HF readmission occurred in 7\% and 8\% of matched patients with LoS 1-5 and > 5 days, respectively $(\mathrm{HR}=1.12 ; 95 \% \mathrm{Cl}: 0.92-1.35 ; p=$ 0.266; Table II). There was no association with HF readmission during longer follow-up.

\section{Length of stay and all-cause mortality in the matched primary cohort}

30-day all-cause mortality occurred in 5\% and $7 \%$ of matched patients with LoS $1-5$ and $>5$ days, respectively $(\mathrm{HR}=1.41 ; 95 \% \mathrm{Cl}: 1.12-1.76$; 
Table I. Baseline characteristics by length of stay, before and after propensity score matching

\begin{tabular}{|c|c|c|c|c|c|c|}
\hline \multirow[t]{3}{*}{ Parameter } & \multicolumn{3}{|c|}{ Before propensity score matching } & \multicolumn{3}{|c|}{ After propensity score matching } \\
\hline & \multicolumn{3}{|c|}{ Length of stay $(n=8049)$} & \multicolumn{3}{|c|}{ Length of stay $(n=5446)$} \\
\hline & $\begin{array}{c}1-5 \text { days } \\
(n=4272)\end{array}$ & $\begin{array}{l}>5 \text { days } \\
(n=3777)\end{array}$ & $P$-value & $\begin{array}{c}1-5 \text { days } \\
(n=2723)\end{array}$ & $\begin{array}{l}>5 \text { days } \\
(n=2723)\end{array}$ & $P$-value \\
\hline Age [years] & $75 \pm 11$ & $76 \pm 11$ & $<0.001$ & $76 \pm 11$ & $76 \pm 11$ & 0.911 \\
\hline Female & $2407(56)$ & $2220(59)$ & 0.028 & $1577(58)$ & $1594(59)$ & 0.640 \\
\hline African American & $1070(25)$ & $924(25)$ & 0.545 & $680(25)$ & $675(25)$ & 0.875 \\
\hline Admission from nursing home & $248(6)$ & $297(8)$ & $<0.001$ & $186(7)$ & $181(7)$ & 0.787 \\
\hline Left ventricular ejection fraction: & & & $<0.001$ & & & 0.947 \\
\hline$<45 \%$ & $1496(35)$ & $1571(42)$ & & $1064(39)$ & $1060(39)$ & \\
\hline$\geq 45 \%$ & $1162(27)$ & $1250(33)$ & & $852(31)$ & $863(32)$ & \\
\hline Unknown & $1614(38)$ & $956(25)$ & & $807(30)$ & $800(29)$ & \\
\hline \multicolumn{7}{|l|}{ Past medical history: } \\
\hline Smoking history & $529(12)$ & $393(10)$ & 0.005 & $285(11)$ & $304(11)$ & 0.407 \\
\hline Prior heart failure & $3025(71)$ & $2787(74)$ & 0.003 & $1972(72)$ & $1962(72)$ & 0.762 \\
\hline Hypertension & $2942(69)$ & $2676(71)$ & 0.053 & $1902(70)$ & $1903(70)$ & 0.976 \\
\hline Coronary artery disease & $2313(54)$ & $2095(56)$ & 0.234 & $1479(54)$ & $1471(54)$ & 0.828 \\
\hline Diabetes mellitus & $1792(42)$ & $1707(45)$ & 0.003 & $1201(44)$ & $1191(44)$ & 0.785 \\
\hline Stroke & 791 (19) & $865(23)$ & $<0.001$ & $564(21)$ & $559(21)$ & 0.867 \\
\hline COPD & $1393(33)$ & $1462(39)$ & $<0.001$ & $988(36)$ & $962(35)$ & 0.462 \\
\hline Dementia & $356(8)$ & $396(11)$ & 0.001 & $239(9)$ & $242(9)$ & 0.886 \\
\hline Cancer & $74(2)$ & $94(3)$ & 0.018 & $59(2)$ & $54(2)$ & 0.635 \\
\hline Atrial fibrillation & $955(22)$ & $1171(31)$ & $<0.001$ & $732(27)$ & $736(27)$ & 0.903 \\
\hline LBBB & $567(13)$ & $512(14)$ & 0.710 & $369(14)$ & $365(13)$ & 0.874 \\
\hline \multicolumn{7}{|l|}{ Clinical and laboratory findings: } \\
\hline Pulse [beats per minute] & $88 \pm 22$ & $91 \pm 23$ & $<0.001$ & $90 \pm 22$ & $90 \pm 23$ & 0.795 \\
\hline Systolic blood pressure [mm Hg] & $152 \pm 33$ & $146 \pm 32$ & $<0.001$ & $149 \pm 32$ & $149 \pm 33$ & 0.738 \\
\hline Pulmonary edema by chest $\mathrm{X}$-ray & $2725(64)$ & $2739(73)$ & $<0.001$ & $1850(68)$ & $1889(69)$ & 0.255 \\
\hline Serum creatinine $[\mathrm{mEq} / \mathrm{l}]$ & $1.58 \pm 1.4$ & $1.64 \pm 1.2$ & 0.035 & $1.62 \pm 1.4$ & $1.60 \pm 1.2$ & 0.672 \\
\hline \multicolumn{7}{|l|}{ In hospital events: } \\
\hline Pneumonia & $777(18)$ & $1271(34)$ & $<0.001$ & $662(24)$ & $657(24)$ & 0.874 \\
\hline Acute myocardial infarction & $121(3)$ & $217(6)$ & $<0.001$ & $101(4)$ & $99(4)$ & 0.885 \\
\hline Pressure ulcer & $186(4)$ & $493(13)$ & $<0.001$ & $176(7)$ & $175(6)$ & 0.956 \\
\hline \multicolumn{7}{|l|}{ Hospital and care characteristics: } \\
\hline Rural hospital & $1548(36)$ & $964(26)$ & $<0.001$ & $822(30)$ & $788(29)$ & 0.313 \\
\hline Cardiology care & $1887(44)$ & $2284(61)$ & $<0.001$ & $1473(54)$ & $1482(54)$ & 0.807 \\
\hline Intensive care & $45(1)$ & $267(7)$ & $<0.001$ & $45(2)$ & $45(2)$ & 1.000 \\
\hline Home health care & $561(13)$ & $853(23)$ & $<0.001$ & $468(17)$ & $458(17)$ & 0.718 \\
\hline Hospice & $54(1)$ & $128(3)$ & $<0.001$ & $49(2)$ & $53(2)$ & 0.689 \\
\hline \multicolumn{7}{|l|}{ Admission medications: } \\
\hline ACE inhibitors and ARB & $2157(51)$ & $1704(45)$ & $<0.001$ & $1268(47)$ & $1296(48)$ & 0.447 \\
\hline$\beta$-Blockers & $1277(30)$ & $1020(27)$ & 0.004 & $764(28)$ & 777 (29) & 0.696 \\
\hline Loop diuretics & $2733(64)$ & $2558(68)$ & $<0.001$ & $1793(66)$ & $1805(66)$ & 0.731 \\
\hline Digoxin & $1545(36)$ & $1351(36)$ & 0.711 & $985(36)$ & $968(36)$ & 0.631 \\
\hline Potassium sparing diuretics & $279(7)$ & $299(8)$ & 0.016 & $194(7)$ & $190(7)$ & 0.832 \\
\hline Potassium supplements & $1595(37)$ & $1471(39)$ & 0.138 & $1056(39)$ & $1044(38)$ & 0.738 \\
\hline
\end{tabular}


Table I. Cont.

\begin{tabular}{|lllllll|}
\hline Parameter & \multicolumn{3}{c}{ Before propensity score matching } & \multicolumn{3}{c|}{ After propensity score matching } \\
\cline { 2 - 7 } & \multicolumn{2}{c}{ Length of stay $(n=8049)$} & \multicolumn{2}{c|}{ Length of stay $(n=5446)$} \\
\cline { 2 - 7 } & $\begin{array}{c}1-5 \text { days } \\
(n=4272)\end{array}$ & $\begin{array}{c}>5 \text { days } \\
(n=3777)\end{array}$ & $P$-value & $\begin{array}{c}1-5 \text { days } \\
(n=2723)\end{array}$ & $\begin{array}{c}>5 \text { days } \\
(n=2723)\end{array}$ & $P$-value \\
\hline Discharge medications: & $2631(62)$ & $2104(56)$ & $<0.001$ & $1614(59)$ & $1622(60)$ & 0.825 \\
\hline ACE inhibitors and ARB & $1325(31)$ & $1111(29)$ & 0.119 & $814(30)$ & $829(30)$ & 0.658 \\
\hline$\beta$-Blockers & $3460(81)$ & $3059(81)$ & 0.998 & $2212(81)$ & $2230(82)$ & 0.529 \\
\hline Loop diuretics & $1741(41)$ & $1674(44)$ & 0.001 & $1172(43)$ & $1167(43)$ & 0.891 \\
\hline Digoxin & $534(13)$ & $609(16)$ & $<0.001$ & $386(14)$ & $386(14)$ & 1.000 \\
\hline Potassium sparing diuretics & $2011(47)$ & $1667(44)$ & 0.008 & $1258(46)$ & $1245(46)$ & 0.724 \\
\hline Potassium supplements & & & & & & \\
\hline
\end{tabular}

Results presented as $n(\%)$ or mean ( $\pm S D$ ).

$p=0.003$; Table II). Of the 2723 matched pairs, in 289 pairs we were able to determine which patient within a matched pair had a shorter 30-day survival, and in 55\% (169/289) of those pairs, they belonged to the longer LoS group (sign-score test $p=0.004$ ). A hidden baseline characteristic would need to increase the odds of having a longer LoS by $12 \%$. HR (95\% Cl) for 30-day all-cause mortality associated with LoS as a continuous variable in the matched data was 1.05 (95\% Cl: 1.03-1.07; $p<0.001)$. The association of a longer LoS with all-cause mortality was attenuated during longer follow-up, but remained significant both at 12 months $(H R=1.16$; 95\% Cl: $1.06-1.27 ; p=0.002)$ and during the overall (8.8 years; median $=2.5$ years) follow-up $(H R=$ 1.13; $95 \% \mathrm{Cl}: 1.06-1.21 ; p<0.001$; Table II and Figure 3). Of the 2723 matched pairs, in 2417 (89\%) pairs we were able to determine which patient within a matched pair had a shorter overall survival, and in 54\% (1293/2417) of those pairs, they belonged to the longer LoS group (sign-score test $p<0.001$ ). $A$ hidden baseline characteristic would need to increase the odds of having a longer LoS by $6 \%$.

Findings from our restricted cubic spline analysis demonstrated that LoS > 10 days is associated with a significantly higher risk for overall all-cause mortality and that there is no evidence that this association is nonlinear ( $p$ for test of non-linearity, $>0.20$ and 0.07 in the matched and pre-match data, respectively (Figure 4). In the prematch cohort, multivariable-adjusted and propensity score-adjusted HRs (95\% Cls) for 30-day allcause mortality associated with LoS $>5$ days were 1.44 (1.17-1.77; $p=0.001)$ and 1.40 (1.14-1.72; $p=0.001)$, respectively.

\section{Findings from the matched sensitivity cohort}

30 -day all-cause readmission occurred in 20\% and $22 \%$ of matched patients with LoS $1-5$ and 6-10 days, respectively $(\mathrm{HR}=1.15$; 95\% Cl: $1.02-$
1.30; $p=0.026$; Table III). 30-day all-cause mortality occurred in $5 \%$ and $6 \%$ of matched patients with LoS $1-5$ and $6-10$ days, respectively ( $H R=1.32$; 95\% Cl: 1.03-1.68; $p=0.027$; Table III). The associations of LoS with other outcomes in the matched sensitivity cohort are displayed in Table III.

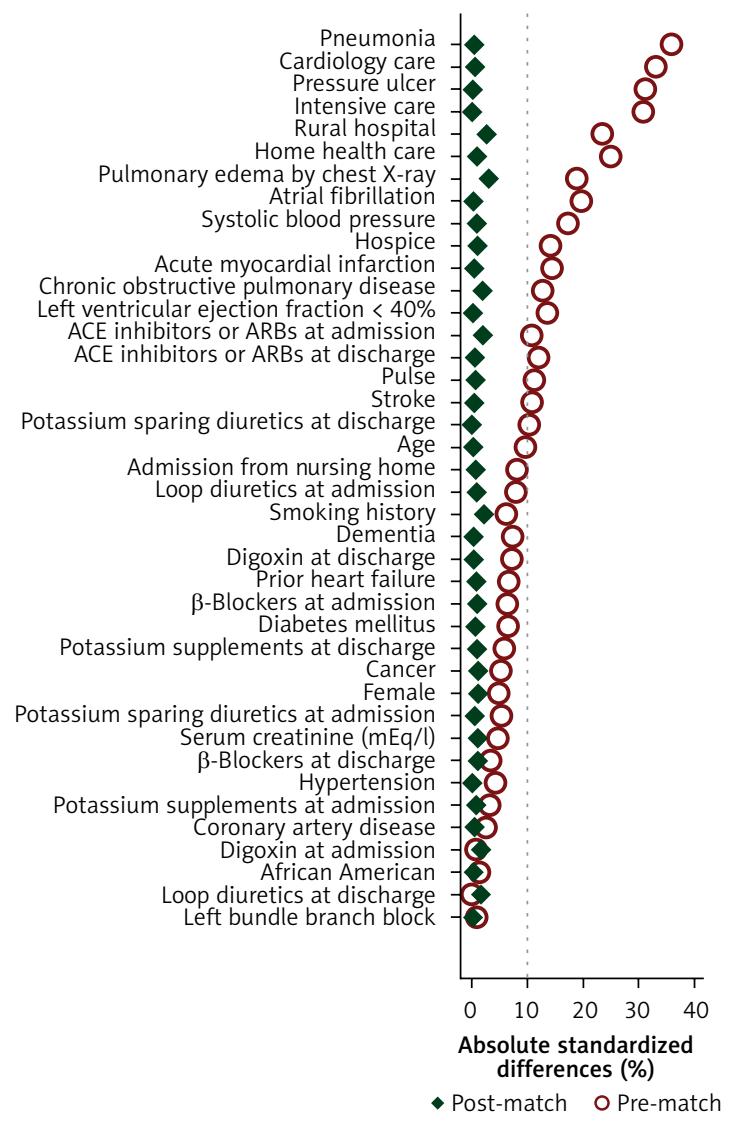

Figure 2. Love plot displaying absolute standardized differences for 40 baseline characteristics between heart failure patients with hospital length of stay $1-5$ versus $>5$ days, before and after propensity score matching

$A C E$ - angiotensin-converting enzyme, $A R B$ - angiotensin receptor blockers. 
Table II. Associations of length of stay with outcomes in a propensity score-matched cohort of 5446 hospitalized patients with heart failure

\begin{tabular}{|c|c|c|c|}
\hline \multirow[t]{2}{*}{ Parameter } & \multicolumn{2}{|c|}{ Length of stay } & \multirow{2}{*}{$\begin{array}{l}\text { Hazard ratios associated } \\
\text { with longer length of stay } \\
\text { (95\% confidence intervals) }\end{array}$} \\
\hline & $\begin{array}{c}1-5 \text { days } \\
(n=2723)\end{array}$ & $\begin{array}{c}>5 \text { days } \\
(n=2723)\end{array}$ & \\
\hline \multicolumn{4}{|l|}{ 30-day outcomes: } \\
\hline All-cause readmission & $20 \%(536)$ & $23 \%(614)$ & $1.16(1.04-1.31) ; p=0.010$ \\
\hline Heart failure readmission & $7 \%(200)$ & $8 \%(221)$ & $1.12(0.92-1.35) ; p=0.266$ \\
\hline All-cause mortality & $5 \%(127)$ & $7 \%(177)$ & $1.41(1.12-1.76) ; p=0.003$ \\
\hline All-cause readmission or mortality & $23 \%(627)$ & $26 \%(717)$ & $1.16(1.04-1.29) ; p=0.006$ \\
\hline \multicolumn{4}{|l|}{ 12-month outcomes: } \\
\hline All-cause readmission & $66 \%(1803)$ & $67 \%(1819)$ & $1.06(0.99-1.13) ; p=0.082$ \\
\hline Heart failure readmission & $32 \%(866)$ & $32 \%(860)$ & $1.04(0.94-1.14) ; p=0.471$ \\
\hline All-cause mortality & $30 \%(827)$ & $34 \%(923)$ & $1.16(1.06-1.27) ; p=0.002$ \\
\hline All-cause readmission or mortality & $76 \%(2058)$ & $77 \%(2086)$ & $1.06(1.00-1.13) ; p=0.046$ \\
\hline \multicolumn{4}{|l|}{ Overall (8.8 years) outcomes: } \\
\hline All-cause readmission & $86 \%(2351)$ & $86 \%(2327)$ & $1.04(0.98-1.10) ; p=0.232$ \\
\hline Heart failure readmission & $57 \%(1557)$ & $56 \%(1523)$ & $1.05(0.98-1.13) ; p=0.178$ \\
\hline All-cause mortality & $66 \%(1794)$ & $70 \%(1903)$ & $1.13(1.06-1.21) ; p<0.001$ \\
\hline All-cause readmission or mortality & $97 \%(2643)$ & $97 \%(2630)$ & $1.04(0.99-1.10) ; p=0.146$ \\
\hline
\end{tabular}

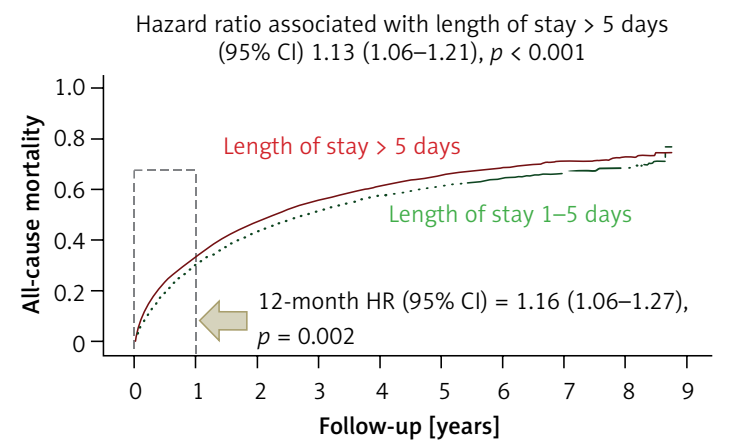

Number at risk by length of stay

$\begin{array}{lllll}1-5 \text { days } 2723 & 1541 & 1370 & 711 & 71 \\ >5 \text { days } 2723 & 1432 & 1057 & 649 & 59\end{array}$

Figure 3. Kaplan Meier plot for all-cause readmis sion in 2723 pairs of propensity score-matched patients with heart failure by length of stay $1-5$ versus $>5$ days

\section{Discussion}

Findings from our study demonstrate that in older patients hospitalized for HF, a LoS > 5 days was associated with a higher risk of 30-day allcause readmission and all-cause mortality, but not with HF readmission. Further, only the association with all-cause mortality persisted during longer follow-up. We also observed that these findings persisted when we excluded patients with LoS $>10$ days. These findings from rigorously assem- bled, propensity score-matched cohorts highlight the complex interplay between LoS and outcomes in older patients with HF.

A potential explanation for these associations include confounding by conditions and complications that may have necessitated the longer LoS $[22,23]$. However, the findings of our study may not be explained by the subset of very sick patients with unusually long LoS, as we found similar results when we repeated our analysis after excluding those with LoS > 10 days. An examination of the baseline characteristics in the pre-match cohort demonstrated that patients in the longer LoS group had a lower mean blood pressure, and a higher prevalence of pre-admission comorbidities, admission pulmonary edema, and in-hospital complications, which have been shown to be associated with poor outcomes [24, 25]. These patients also had a lower prevalence of pre-admission use of ACE inhibitors and $\beta$-blockers, drugs known to improve outcomes [26, 27]. Although the distribution of these and other baseline characteristics was balanced after propensity score-matching, imbalanced unmeasured characteristics such as disease severity may act as confounders. For example, although the prevalence of pneumonia was similar after matching, it is possible that pneumonia in the longer LoS group was more severe or complicated. A longer LoS may also lead to 
A

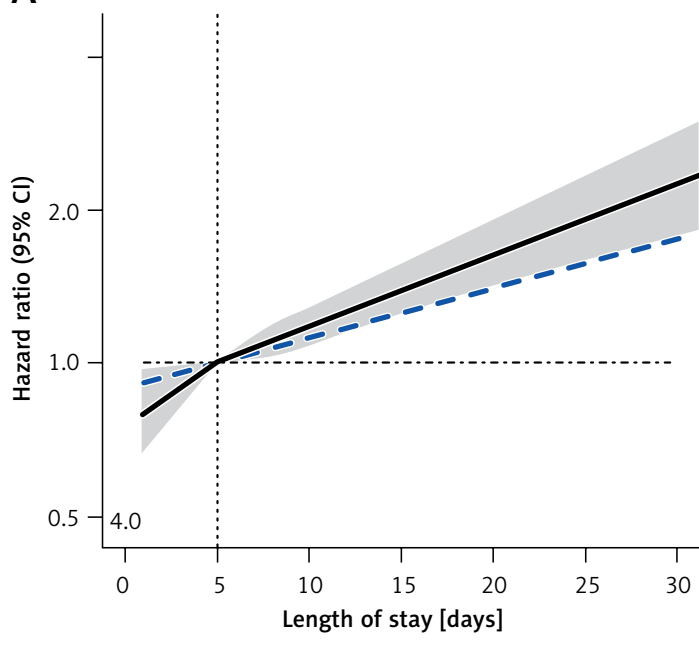

_ Cubic spline $(95 \% \mathrm{Cl}) \quad$ - - - - - Linear model
B

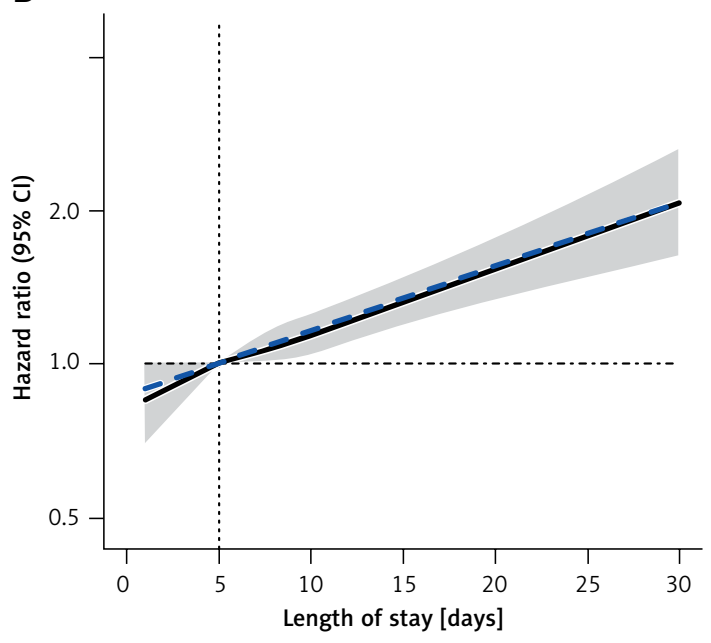

— Cubic spline $(95 \% \mathrm{Cl}) \quad$ - - - - Linear model

Figure 4. Restricted cubic spline regression analysis displaying risk of all-cause mortality during 8.8 (median $=2.5)$ years of follow-up by hospital length of stay in days as a continuous variable in patients with heart failure using 3 knots at length of stay 3, 5 (reference), 7 and 10 days. Solid black lines represent hazard ratios and shaded areas represent $95 \%$ confidence intervals. Plots on the left panel (A) are based on 8049 pre-match patients, adjusting for propensity scores, and those on the right panel (B) are based on 5446 propensity score-matched patients balanced on 40 baseline characteristics (non-linearity $p>0.2$ for matched and 0.07 for pre-match patients)

Table III. Associations of length of stay with outcomes in a propensity score-matched cohort of 4798 hospitalized patients with heart failure that excluded those with length of stay $>10$ days

\begin{tabular}{|c|c|c|c|}
\hline \multirow[t]{2}{*}{ Parameter } & \multicolumn{2}{|c|}{ Length of stay } & \multirow{2}{*}{$\begin{array}{l}\text { Hazard ratios associated } \\
\text { with longer length of stay } \\
\text { ( } 95 \% \text { confidence intervals) }\end{array}$} \\
\hline & $\begin{array}{c}1-5 \text { days } \\
(n=2399)\end{array}$ & $\begin{array}{l}6-10 \text { days } \\
(n=2399)\end{array}$ & \\
\hline \multicolumn{4}{|l|}{ 30-day outcomes: } \\
\hline All-cause readmission & $20 \%(470)$ & $22 \%(532)$ & $1.15(1.02-1.30) ; p=0.026$ \\
\hline Heart failure readmission & $7 \%(176)$ & $8 \%(199)$ & $1.14(0.93-1.40) ; p=0.200$ \\
\hline All-cause mortality & $5 \%(113)$ & $6 \%(148)$ & $1.32(1.03-1.68) ; p=0.027$ \\
\hline All-cause readmission or mortality & $23 \%(552)$ & $26 \%(616)$ & $1.14(1.01-1.27) ; p=0.030$ \\
\hline \multicolumn{4}{|l|}{ 12-month outcomes: } \\
\hline All-cause readmission & $65 \%(1560)$ & $67 \%(1602)$ & $1.07(1.00-1.15) ; p=0.050$ \\
\hline Heart failure readmission & $32 \%(770)$ & $32 \%(777)$ & $1.04(0.94-1.15) ; p=0.422$ \\
\hline All-cause mortality & $30 \%(728)$ & $33 \%(797)$ & $1.13(1.02-1.25) ; p=0.019$ \\
\hline All-cause readmission or mortality & $74 \%(1786)$ & $76 \%(1829)$ & $1.07(1.00-1.14) ; p=0.046$ \\
\hline \multicolumn{4}{|l|}{ Overall (8.8 years) outcomes: } \\
\hline All-cause readmission & $86 \%(2057)$ & $86 \%(2055)$ & $1.05(0.99-1.12) ; p=0.101$ \\
\hline Heart failure readmission & $57 \%(1375)$ & $57 \%(1365)$ & $1.06(0.99-1.14) ; p=0.116$ \\
\hline All-cause mortality & $66 \%(1581)$ & $70 \%(1667)$ & $1.12(1.05-1.20) ; p=0.001$ \\
\hline All-cause readmission or mortality & $97 \%(2316)$ & $97 \%(2314)$ & $1.05(0.99-1.11) ; p=0.086$ \\
\hline
\end{tabular}

a higher prevalence of unmeasured confounders such as loss of function, strength, coordination, and mobility [28, 29].

Several prior studies have examined the association of LoS with outcomes in patients hos- pitalized for HF [5-7]. Among 19,927 hospitalized patients with HF (2008-2011), compared with LoS 3-4 days, LoS 5-10 days was associated with a $17 \%$ higher risk of 30-day all-cause readmission and a $52 \%$ higher risk of 30-day all-cause mortal- 
ity, but had no association with HF readmission [6]. The mean age of the patients in that study and their 30-day outcome rates are similar to those in our study [6]. However, our study is distinguished by the use of propensity score matching, which allowed us to achieve and display balance in key measured baseline characteristics between the two LoS groups. Taken together, these findings suggest that a longer LoS has a stronger association with mortality than with readmission. Future studies need to examine underlying reasons why a longer LoS may increase the risk of death, but not of readmission, and develop and test interventions that may improve post-discharge survival among the high-risk subset of patients with longer LoS.

Our study has several limitations. As in any observational study, bias due to an unmeasured confounder is possible. Although the management of heart failure with reduced ejection fraction has evolved, the findings of the current study are similar to those observed in a more contemporary population of HF patients [6]. Additionally, we had no data on brain natriuretic peptides, the use of vasodilators, sacubitril/valsartan, or inotropic drugs, and drug-drug interactions [30-34].

In conclusion, in older adults hospitalized for $\mathrm{HF}$, when compared with a hospital length of stay of 1-5 days, a length of stay of 5-10 days is associated with a higher risk of both mortality and short-term readmission, but not with HF readmission.

\section{Acknowledgments}

Dr. Ahmed was in part supported by the National Institutes of Health through grants (R01HL085561, R01-HL085561-S and R01-HL097047) from the National Heart, Lung, and Blood Institute. Dr. Fonarow reports consulting with Abbott, Amgen, Bayer, Janssen, Novartis, and Medtronic.

Prior presentations: Presented as an abstract at the American Heart Association meeting in 2015.

\section{Conflict of interest}

The authors declare no conflict of interest.

\section{References}

1. Bueno H, Ross JS, Wang Y, et al. Trends in length of stay and short-term outcomes among Medicare patients hospitalized for heart failure, 1993-2006. JAMA 2010; 303: 2141-7.

2. Ahmed A, Bourge RC, Fonarow GC, et al. Digoxin use and lower 30-day all-cause readmission for Medicare beneficiaries hospitalized for heart failure. Am J Med 2014; 127: 61-70.

3. Shih T, Chen LM, Nallamothu BK. Will bundled payments change health care? Examining the evidence thus far in cardiovascular care. Circulation 2015; 131: 2151-8.
4. Chee TT, Ryan AM, Wasfy JH, Borden WB. Current state of value-based purchasing programs. Circulation 2016; 133: 2197-205.

5. Khan H, Greene SJ, Fonarow GC, et al. Length of hospital stay and 30-day readmission following heart failure hospitalization: insights from the EVEREST trial. Eur J Heart Fail 2015; 17: 1022-31.

6. Reynolds K, Butler MG, Kimes TM, Rosales AG, Chan W, Nichols GA. Relation of acute heart failure hospital length of stay to subsequent readmission and all-cause mortality. Am J Cardiol 2015; 116: 400-5.

7. Sud M, Yu B, Wijeysundera HC, et al. Associations between short or long length of stay and 30-day readmission and mortality in hospitalized patients with heart failure. JACC Heart Fail 2017; 5: 578-88.

8. Feller MA, Mujib M, Zhang Y, et al. Baseline characteristics, quality of care, and outcomes of younger and older Medicare beneficiaries hospitalized with heart failure: findings from the Alabama Heart Failure Project. Int J Cardiol 2012; 162: 39-44.

9. Ahmed A, Fonarow GC, Zhang Y, et al. Renin-angiotensin inhibition in systolic heart failure and chronic kidney disease. Am J Med 2012; 125: 399-410.

10. Ahmed A, Rich MW, Zile M, et al. Renin-angiotensin inhibition in diastolic heart failure and chronic kidney disease. Am J Med 2013; 126: 150-61.

11. Arundel C, Sheriff H, Bearden DM, et al. Discharge home health services referral and 30-day all-cause readmission in older adults with heart failure. Arch Med Sci 2018; 14: 995-1002.

12. Arundel C, Lam PH, Khosla R, et al. Association of 30-day all-cause readmission with long-term outcomes in hospitalized older medicare beneficiaries with heart failure. Am J Med 2016; 129: 1178-84.

13. Sheriff HM, Thogaripally MR, Panjrath G, et al. Digoxin and 30-day all-cause readmission in long-term care residents hospitalized for heart failure. J Am Med Dir Assoc 2017; 18: 761-5.

14. Dugan J, Virani SS, Ho V. Medicare eligibility and physician utilization among adults with coronary heart disease and stroke. Med Care 2012; 50: 547-53.

15. Rosenbaum PR, Rubin DB. The central role of propensity score in observational studies for causal effects. Biometrika 1983; 70: 41-55.

16. Rubin DB. Using propensity score to help design observational studies: application to the tobacco litigation. Health Services Outcomes Res Methodol 2001; 2: 169-88.

17. Ahmed A, Husain A, Love TE, et al. Heart failure, chronic diuretic use, and increase in mortality and hospitalization: an observational study using propensity score methods. Eur Heart J 2006; 27: 1431-9.

18. Ahmed A, Rich MW, Love TE, et al. Digoxin and reduction in mortality and hospitalization in heart failure: a comprehensive post hoc analysis of the DIG trial. Eur Heart J 2006; 27: 178-86.

19. Tsimploulis A, Lam PH, Arundel C, et al. Systolic blood pressure and outcomes in patients with heart failure with preserved ejection fraction. JAMA Cardiol 2018; 3: 288-97.

20. Lam PH, Dooley DJ, Deedwania P, et al. Heart rate and outcomes in hospitalized patients with heart failure with preserved ejection fraction. J Am Coll Cardiol 2017; 70: 1861-71.

21. Rosenbaum PR. Sensitivity to hidden bias. In: Observational Studies. Rosenbaum PR (eds). Springer-Verlag, New York 2002; 105-70.

22. Pierre-Louis B, Rodriques S, Gorospe V, et al. Clinical factors associated with early readmission among acutely 
decompensated heart failure patients. Arch Med Sci 2016; 12: 538-45.

23. Balasubramaniyam N, Palaniswamy C, Aronow WS, et al. Association of corrected QT interval with long-term mortality in patients with syncope. Arch Med Sci 2013; 9: 1049-54.

24. Gheorghiade M, Abraham WT, Albert NM, et al. Systolic blood pressure at admission, clinical characteristics, and outcomes in patients hospitalized with acute heart failure. JAMA 2006; 296: 2217-26.

25. Roguin A, Behar D, Ben Ami H, et al. Long-term prognosis of acute pulmonary oedema: an ominous outcome. Eur J Heart Fail 2000; 2: 137-44.

26. Bhatia V, Bajaj NS, Sanam K, et al. Beta-blocker use and 30-day all-cause readmission in Medicare beneficiaries with systolic heart failure. Am J Med 2015; 128: 715-21.

27. Sanam K, Bhatia V, Bajaj NS, et al. Renin-angiotensin system inhibition and lower 30-day all-cause readmission in medicare beneficiaries with heart failure. Am J Med 2016; 129: 1067-73.

28. Krumholz HM. Post-hospital syndrome: an acquired, transient condition of generalized risk. N Engl J Med 2013; 368: 100-2.

29. Orimoloye OA, Kambhampati S, Hicks AJ $3^{\text {rd }}$, et al. Higher cardiorespiratory fitness predicts long-term survival in patients with heart failure and preserved ejection fraction: the Henry Ford Exercise Testing (FIT) Project. Arch Med Sci 2019; 15: 350-8.

30. Aronow WS. Update of treatment of heart failure with reduction of left ventricular ejection fraction. Arch Med Sci Atheroscler Dis 2016; 1: e106-16.

31. Roblek T, Trobec K, Mrhar A, Lainscak M. Potential drugdrug interactions in hospitalized patients with chronic heart failure and chronic obstructive pulmonary disease. Arch Med Sci 2014; 10: 920-32.

32. Yandrapalli S, Aronow WS, Mondal P, Chabbott DR. The evolution of natriuretic peptide augmentation in management of heart failure and the role of sacubitril/valsartan. Arch Med Sci 2017; 13: 1207-16.

33. Michalska-Kasiczak M, Bielecka-Dabrowa A, von Haehling S, Anker SD, Rysz J, Banach M. Biomarkers, myocardial fibrosis and co-morbidities in heart failure with preserved ejection fraction: an overview. Arch Med Sci 2018; 14: 890-909.

34. Kadri AN, Kaw R, Al-Khadra $Y$ et al. The role of B-type natriuretic peptide in diagnosing acute decompensated heart failure in chronic kidney disease patients. Arch Med Sci 2018; 14: 1003-9. 